\title{
Nörogelişimsel problemler açısından yükssek riskli bebeklerde erken tanı ve izlem prensipleri
}

\author{
Early diagnosis and follow-up principles in high-risk infants in terms of \\ neurodevelopmental problems
}

\author{
İpek Akman ${ }^{1}$, Nilüfer Eldeş Hacıfazlıoğlu ${ }^{2}$
}

${ }^{1}$ Bahçeşehir Üniversitesi, Çocuk Sağ|ı̆̆ı ve Hastalıkları Anabilim Dalı, Neonatoloji Bilim Dalı, İstanbul
2Zeynep Kamil Kadın Doğum ve Çocuk Hastanesi, Çocuk Nörolojisi Bölümü, İstanbul

\begin{abstract}
Riskli bebekler prematürite, intrauterin büyüme geriliği, doğumsal enfeksiyon, neonatal ensefalopati, neonatal konvülziyon ve solunum sıkıntısı gibi tanılar alıp yenidoğan yoğun bakım ünitelerinde takip edilen bebeklerdir. Riskli bebekler gelişme geriliği, sensörinöral problemler (görme, işitme ve konuşma bozuklukları), dil geriliği, davranışsal sorunlar ve psikososyal problemler açısından risk altındadırlar. Çok düşük doğum ağırlıklı bebeklerin yaklaşık \%5-10'unda serebral palsi (SP), \%25'inde bilişsel problemler veya davranış problemleri görülebilir. íkizlerde, prematürelik ve intrauterin büyüme geriliği riski ve tekiz bebeklere göre SP riski yedi kat fazladır. Perinatal asfiksi sonucu hastaların \%30'unda SP, \%45'inde bilişsel ve gelişimsel sorunlar görülür. Riskli bebeklerin taburculuk öncesi ve sonrası takipleri yenidoğan uzmanı, genel pediatrist, çocuk nöroloji uzmanı, odyoloji, çocuk gelişim uzmanı, göz uzmanı, fizyoterapist, solunum terapisti, konuşma ve dil terapistinin ve diyetisyenin de içinde bulunduğu farklı disiplinlerden gelen bir ekip tarafından yapılmalıdır. Riskli bebek takibinin amacı, bu bebeklerin erken dönemde sorunlarını tespit etmek ve erken müdahalelerle prognozu iyileştirmek; böylece bebeğin ve ailenin yaşam kalitesini arttırmaktır.
\end{abstract}

Anahtar sözcükler: prematürite; riskli bebek; nörogelişimsel prognoz; sensörinöral problemler
Risky babies are infants who are followed up in neonatal intensive care units with diagnoses such as prematurity, intrauterine growth retardation, congenital infection, neonatal encephalopathy, neonatal convulsions, and respiratory distress. Risky infants are at risk for developmental delay, sensorineural problems (vision, hearing and speech disorders), language stress, behavioral problems and psychosocial problems. Cerebral palsy (CP) can be seen in about $5-10 \%$ of very low birth weight infants, and cognitive or behavior problems in $25 \%$. In twins, the risk of prematurity and intrauterine growth retardation and the CP risk increases 7 times compared to single infants. Of the patients with perinatal asphyxia, cerebral palsy is seen in $30 \%$, and cognitive and developmental problems is seen in $45 \%$. Before and after discharge the follow-up of risky babies should be done by a team from different disciplines including neonatologist, general pediatrician, pediatric neurologist, audiologist, child development specialist, eye specialist, physiotherapist, respiratory therapist, speech and language therapist, and dietitian. The aim of risky baby follow-up is to detect the problems of these babies in early period, and to improve the prognosis with early interventions; and by so, to increase the quality of life of the baby and the family.

Key words: prematurity; risky infant; neurodevelopmental prognosis; sensorineural problems
$\mathbf{R}$ iskli bebek terimi daha çok gelişme geriliği, sensörinöral problemler (görme, işitme ve konuşma bozuklukları), dil geriliği, davranışsal sorunlar ve psikososyal problemler açısından risk altında olan bebekleri ifade etmek için kullanılmaktadır. Başka bir deyişle anneye bağlı, gebelik ve doğum sırasında yaşanan sorunlara bağlı ya da doğum sonrası erken dönemde yaşanan olaylara bağlı olarak nörolojik açıdan gelişme geriliği görülebilecek bebeklere riskli bebek denir. Riskli bebeklerin en kısa zamanda tespit edilmeleri erken tanı ve girişimi mümkün kıldığından çok önemlidir. Riskli bebeklerin erken dönemde tespit edilmesi ancak ayrıntılı bir anamnez, tam bir fizik muayene ve gelişimin değerlendirilmesi ile mümkündür. Riskli bebek doğumu ile ilişkili faktörler Tablo 1'de özetlenmiştir. ${ }^{[1]}$

- İletişim adresi: Prof. Dr. İpek Akman, Bahçeşehir Üniversitesi, Çocuk Sağlığı ve Hastalıkları Anabilim Dalı, Neonatoloji Bilim Dalı, İstanbul Tel: 0533 - 3506759 e-posta: ipekakman@yahoo.com

- Geliș tarihi: 1 Ekim $2018 \quad$ Kabul tarihi: 1 Ekim 2018 
Tablo 1. Riskli bebek doğumu ile ilişkili etkenler

\begin{tabular}{|c|c|c|}
\hline Antenatal Nedenler & Natal Nedenler & Postnatal Nedenler \\
\hline Takipsiz gebelik & Preterm doğum & Doğum kilosunun <2500 gr \\
\hline Gebelikte yasa dışı ilaç, alkol ve sigara kullanımı & Postterm doğum & ya da $>4000$ gr olması \\
\hline \multirow{2}{*}{$\begin{array}{c}\text { Annenin kronik hastalıkları (diyabet, hipertansiyon, } \\
\text { doğumsal kalp hastalığı, böbrek yetmezliği) }\end{array}$} & Erken membran yırtı̆̆ı & Yenidoğan döneminde sepsis, menenjit \\
\hline & Doğum travması & Beyin kanaması \\
\hline Hamilelik döneminde geçirilen enfeksiyonlar & Perinatal asfiksi & Beslenme yetersizliği, hipoglisemi \\
\hline Doğumsal anomali & \multirow{2}{*}{$\begin{array}{l}\text { Rahim içi kanama } \\
\quad \text { (plasenta dekolmanı) }\end{array}$} & \multirow{2}{*}{$\begin{array}{l}\text { Solunum yetmezliği ve } \\
\text { ventilatörde kalma öyküsü }\end{array}$} \\
\hline İntrauterin büyüme geriliği & & \\
\hline Çoğul gebelik & \multirow[t]{2}{*}{ Mekonyumlu doğum } & \multirow[t]{2}{*}{ Hiperbilirübinemi } \\
\hline Preeklampsi, eklampsi & & \\
\hline Plasenta previa & & \\
\hline
\end{tabular}

\section{PREMATÜRITE}

Gestasyon haftası 37 haftadan küçük bebekler prematüre olarak tanımlanır. Preterm doğum oranı dünyada \%11 dir. Preterm doğan bebeklerin ise \%84'ü 3236 hafta, \%10'u 28-32 hafta, \%5'i 28 haftanın altında doğan bebeklerdir. Doğum haftası 34 0/7 ile 36 6/7 hafta arasında olan bebekler geç preterm, 32 hafta ile 34 hafta arası olan bebekler preterm, 28 hafta ile 32 hafta arası olanlar erken preterm 28 haftadan küçük doğan bebekler ise çok erken preterm bebekler olarak tanımlanırlar. ${ }^{[2]}$ Prematüre bebekler doğum ağırlıklarına (DA) göre düşük doğum ağırlıklı (LBW) (DA <2500 gr), çok düşük doğum ağılıklı (VLBW) (DA <1500 gr) ya da ileri derece düşük doğum ağırlıklı (ELBW) (DA $<1000$ gr) olarak üç gruba ayrılabilir.

Nörogelişimsel gerilik tanısı bilişsel, nörolojik, duyusal problemler varlığında konulur ve aşağıdaki değerlendirmelerden bir ya da ikisinde anormallik olması durumunda değerlendirilir.

1) Standart gelişimsel değerlendirme testlerinden birinde -2 standart sapmadan daha fazla gerilik olması,

2) Kaba Motor Fonksiyon Sınıflandırma Sistemine (GMFCS) göre iki veya daha üzerinde bir kategoride SP olması,

3) İşitme kaybı,

4) Görme keskinliğinin $20 / 100$ 'ün altında olması,

Ek olarak davranışsal, psikolojik ve fonksiyonel problemler de nörogelişimsel anormallik olarak tanımlanmaktadır. Nörogelişimsel anormallik riski doğum haftası ve doğum ağırlığı azaldıkça artar..$^{[3]}$

\section{ileri Derece Düşük Doğum Ağırıklı Bebekler (EVLBW)}

İngiltere'de yapılmış EPICure çalışmasında 25 haftanın altında doğan bebekler 30 . ay ve 6,11 ve 19 yaşlarında nörogelişimsel anomaliler açısından değerlendirilmişlerdir. Otuzuncu ay değerlendirmesinde, gelişimsel gerilik $\% 30$, işitme kaybı $\% 3$ ve görme problemleri \%2 oranında tespit edilmiştir. ${ }^{[4]}$ Altı yaş değerlendirmesinde ciddi, orta ve hafif nörogelişimsel gerilik sırasıyla \%22, \%24, \%34 oranlarında tespit edilmiştir. On bir yaş değerlendirmesinde serebral palsi \%40, görme problemi $\% 9$, işitme problemi ise $\% 2$ oranında tespit edilmiştir. ${ }^{[5]}$ Gestasyon haftası düştükçe mortalite ve morbiditenin belirgin olarak arttığı gösterilmiştir. Gestasyon haftaları çok düşük olan prematüre bebeklerin bilişsel ve nöromotor morbidite durumları ile ilgili bazı çalışmaların sonuçları Tablo 2'de özetlenmiştir.

\section{Çok Düşük Doğum Ağırlıklı Bebekler (VLBW)}

Çok düşük doğum ağırlıklı bebeklerde yapılan bir çalışmada serebral palsi oranı \%9 olarak bulunmuş, bu olguların \%20'sinin hiç yürüyemediği; 24-28 hafta arasında doğan bebeklerin \%40'ının, 29-32 hafta arasında doğan bebeklerin ise \%30'unun fizyoterapi, konuşma terapisi, psikiyatrik tedavi, iş uğraş terapisi gibi özel gereksinimleri olduğu tespit edilmiştir. ${ }^{[7]}$

Yenidoğan döneminde ciddi beyin hasarı (3. ve 4. derece intraventriküler kanama, kistik periventriküler lökomalazi, intraparankimal beyin kanaması) olan bebeklerde motor, bilişsel, davranışsal, görme, işitme, psikiyatrik (otizm spektrum bozukluğu ve obsesif kompulsif bozukluk) problemlerin olma riski daha yüksektir. ${ }^{[10]}$ 
Tablo 2. Gestasyon haftaları çok düşük olan prematüre bebeklerin bilişsel ve nöromotor morbidite durumları

\begin{tabular}{|c|c|c|c|c|c|c|c|}
\hline \multirow[b]{2}{*}{ Çalışma } & \multirow[b]{2}{*}{ Çalışma yılı } & \multirow[b]{2}{*}{ Prognoz } & \multicolumn{5}{|c|}{ Doğum haftasına göre oran (\%) } \\
\hline & & & 22 & 23 & 24 & 25 & Toplam \\
\hline \multirow[t]{2}{*}{ EPICure $^{[6]}$} & 1995 & Serebral palsi & $\mathrm{N} / \mathrm{A}$ & 13 & 21 & 20 & 20 \\
\hline & & $\mathrm{K}-\mathrm{ABC}$ testi $<70$ & $\mathrm{~N} / \mathrm{A}$ & 11 & 14 & 7 & 10 \\
\hline \multirow[t]{2}{*}{ Epipage $e^{[7]}$} & 1997 & Serebral palsi & $\mathrm{N} / \mathrm{A}$ & 33 & 13 & 16,3 & 16 \\
\hline & & $\mathrm{K}-\mathrm{ABC}$ testi $<70$ & $\mathrm{~N} / \mathrm{A}$ & 0 & 23 & 12 & 14 \\
\hline \multirow[t]{2}{*}{ Tyson ${ }^{[3]}$} & 1998-2003 & $\mathrm{MDI} / \mathrm{PDI}<70$ & 80 & 65 & 50 & 36 & 47 \\
\hline & & $\mathrm{MDI} / \mathrm{PDI}<50$ & 60 & 38 & 23 & 17 & 24 \\
\hline \multirow[t]{2}{*}{ Ishi ${ }^{[8]}$} & 2003-2005 & $\begin{array}{l}\text { Orta-ağır SP, İşitme kaybı, } \\
\text { Tek veya her iki gözde görme kaybı, } \\
\text { KSPD }<70\end{array}$ & 52 & 57 & 37 & 37 & 42 \\
\hline & & $\begin{array}{l}\text { Ağır SP } \\
\text { KSPD }<50\end{array}$ & 30 & 40 & 16 & 17 & 23 \\
\hline \multirow[t]{3}{*}{ Serenius $^{[9]}$} & 2004-2007 & $\begin{array}{l}\text { Bayley III, } \\
-1 \text { ile }-2 \text { SD arasında (DY: } 2,5 \text { yaş) }\end{array}$ & 40 & 19 & 33 & 29 & 29 \\
\hline & & $\begin{array}{l}\text { Bayley III, } \\
-2 \text { ile }-3 \text { SD arasında (DY: } 2,5 \text { yaş) }\end{array}$ & 20 & 30 & 21 & 17 & 20 \\
\hline & & $\begin{array}{l}\text { Bayley III, } \\
\text { <-3 SD (DY: } 2,5 \text { yaş) }\end{array}$ & 40 & 21 & 13 & 10 & 13 \\
\hline
\end{tabular}

K-ABC test: Mental Processing Composite of the Kaufman Assessment Battery for Children.

MDI: Mental Developmental Index of the Bayley Scales of Infant Development-II (Düzeltilmis yaș 18-22 ay).

PDI: Psychomotor Developmental Index of the Bayley Scales of Infant Development-II (düzeltilmiş yaş 18-22 ay).

KSPD: 36 to 42 months corrected age on the Kyoto Scale of Psychological Development.

\section{NEONATAL ENSEFALOPATi}

Neonatal ensefalopati metabolik, hipoksik-iskemi, travma, inme ve menenjit gibi etkenlere bağlı gelişebilen; hipereksitabilite, koma ve nöbetler ile karakterize bir durumdur. Term bebeklerde neonatal ensefalopati görülme sıklığı 6/1000'dir. ${ }^{[11]}$ Neonatal ensefalopatinin klinik özellikleri bilinç düzeyinde azalma, hipotoni, spontan hareketlerde azalma, periyodik solunum ya da apne ve nöbetlerdir. Beyin sapının etkilendiği durumlarda okülomotor ve pupiller bozukluklar ve ögürme refleksinin yokluğu gibi bulgular da gözlenebilir. Hipoksik iskemik ensefalopati (HIE) sonrası beyin hasarının yaygınlığı asfiksi derecesine bağlıdır. HiE hafif, orta ve ağır ensefalopati olarak kategorize edilmiştir. ${ }^{[12]}$ Hafif HiE olan olguların çoğu normal olarak gelişirken, ağır HiE geçiren bebeklerde ciddi nöromotor gelişme geriliği riski çok yüksektir. Eğer ensefalopati kernikterusa bağlı ise, bu bebeklerde atetoz ve bakış anormallikleri (genellikle yukarı bakış) şeklinde izlenen ekstrapiramidal bulgular görülür.

\section{DOĞUMSAL ENFEKSIYYNLAR}

En sık görülen doğumsal enfeksiyonlar Sitomegalovirüs (CMV), Herpes Simpleks Virüs (HSV), varisella, sifiliz, toksoplazmozis, rubella, parvovirüs
B19, Grup B streptokok, tüberküloz ve listeriyosiz olarak sıralanabilir. ${ }^{[13]}$ Fetal dönemde bu enfeksiyonların gelişmekte olan organlar üzerine etkileri çok yıkıcı olmaktadır. Tablo 3'te bazı doğumsal enfeksiyonlar ve özellikleri özetlenmiştir. ${ }^{[14]}$

\section{INTRAUTERIN BÜYÜME GERILIĞi (IUBG)}

iUBG, bebeğin doğum ağırlığının 10. persentilin altında olması olarak tanımlanmıştır. Büyüme geriliğinin gestasyonun erken dönemlerinde başlaması, tartı boy ve baş çevresinin benzer şekilde etkilendiği simetrik büyüme geriliğine neden olmaktadır. Simetrik büyüme geriliğinin nedenleri olarak genetik hastalıklar (trizomiler, diğer kromozom bozuklukları ve konstitüsyonel durumlar), boy kısalığı sendromları, doğumsal viral enfeksiyonlar, bazı doğumsal metabolik hastalıklar ve intrauterin ilaç maruziyeti sıralanabilir. Gebeliğin sonlarında başlayan asimetrik büyüme geriliği ise genellikle uteroplasental fonksiyonun bozulması (preeklampsi, kronik hipertansiyon, diabetes mellitus) ya da besin eksikliği ile ilişkilidir. ${ }^{[15]}$

IUBG olan bebeklerin perinatal mortalite oranları, doğum ağırlıkları haftasına uygun (AGA) bebeklere kıyasla 10-20 kat artmıştır. ${ }^{[16]}$ iUBG olan fetüslerde en önemli sorun perinatal asfiksidir. Kronik 
Tablo 3. Bazı doğumsal enfeksiyonlar ve klinik özellikleri

\begin{tabular}{|c|c|c|c|}
\hline Doğumsal Enfeksiyon & Doğumsal Anatomik Defekt & Neonatal Organ Tutulumu & Geç Sekeller \\
\hline Toksoplazmoz & $\begin{array}{l}\text { Mikroftalmi, mikrosefali, } \\
\text { hidrosefali, IUBG* }\end{array}$ & $\begin{array}{l}\text { Lenfadenopati, trombositopeni, } \\
\text { pnömoni, ensefalit, koryoretinit, } \\
\text { purpura, hepatosplenomegali, } \\
\text { sarılık, anemi, hidrops fetalis, }\end{array}$ & $\begin{array}{l}\text { İşitme kaybı, serebral } \\
\text { kalsifikasyon, mental } \\
\text { retardasyon, konvülziyon. }\end{array}$ \\
\hline Parvovirus & Anemi & Hidrops fetalis & \\
\hline Varisella & Ekstremite hipoplazisi, IUBG & Cilt lezyonları, pnömoni & Mental retardasyon \\
\hline Rubella & $\begin{array}{l}\text { Katarakt, mikroftalmi, pigmenter } \\
\text { retinopati, doğumsal glakom, } \\
\text { PDA** }^{* *} \text { periferik pulmonerstenoz, } \\
\text { IUBG, polimikrogiri, mikrosefali, } \\
\text { hidrosefali }\end{array}$ & $\begin{array}{l}\text { Osteit, lenfadenopati, peteşi, } \\
\text { purpura, trombositopeni, cilt } \\
\text { lezyonları, retinit, pnömoni, } \\
\text { hepatosplenomegali, anemi, } \\
\text { ensefalit, koryoretinit }\end{array}$ & $\begin{array}{l}\text { Sensörinöral işitme kaybı, } \\
\text { davranış problemleri ve mental } \\
\text { retardasyon, konvülziyon, dental/ } \\
\text { iskelet problemleri. }\end{array}$ \\
\hline Sifiliz & $\begin{array}{l}\text { Hidrops fetalis, preterm doğum, } \\
\text { intersitisyel keratit, IUBG, anemi }\end{array}$ & $\begin{array}{l}\text { Osteit, lenfadenopati, rinit, } \\
\text { trombositopeni, cilt lezyonları, } \\
\text { retinitis }\end{array}$ & $\begin{array}{l}\text { Sensörinöral işitme kaybı, mental } \\
\text { retardasyon, nefrotik sendrom, } \\
\text { dental/iskelet problemleri. }\end{array}$ \\
\hline $\mathrm{HSV}^{* * *}$ & $\begin{array}{l}\text { Ensefalit, hepatit, mikrosefali, } \\
\text { hidrosefali }\end{array}$ & $\begin{array}{l}\text { Trombositopeni, cilt lezyonları, } \\
\text { retinit }\end{array}$ & $\begin{array}{l}\text { Mental retardasyon, } \\
\text { konvülziyonlar. }\end{array}$ \\
\hline $\mathrm{CMV}^{* * * *}$ & $\begin{array}{l}\text { Mikrosefali, ensefalit, } \\
\text { koryoretinit, hipotoni, IUBG, } \\
\text { hepatosplenomegali, hepatit, } \\
\text { mikroftalmi, mikrogiri, anemi, }\end{array}$ & $\begin{array}{l}\text { Peteşi, purpura, trombositopeni, } \\
\text { lenfadenopati, pnömoni, retinit. }\end{array}$ & $\begin{array}{l}\text { İşitme kaybı, mental retardasyon, } \\
\text { serebral klasifikasyon, } \\
\text { konvülziyonlar. }\end{array}$ \\
\hline $\begin{array}{l}\text { * Intrauterin büyüme geriliği } \\
\text { ** Patent duktus arteriyozus } \\
\text { ** Herpes simpleks virüs } \\
\text { *** Sitomegalovirüs }\end{array}$ & & & \\
\hline
\end{tabular}

intrauterin hipoksi eritropoietin sentezini indüklediğinden IUBG olan fetüslerde polisitemi oldukça sık gözlenmektedir. ${ }^{[17]}$ iUBG'nde görülen kronik hipoksi, antioksidan kapasitesinde azalma ve büyüme hormon düzeylerindeki değişiklikler bu bebekleri pulmoner direnç artışına karşı duyarlı hale getirmektedir. Doğum yaşına göre küçük doğan (SGA) prematüre bebeklerde nekrotizan enterokolit riski, AGA prematürelere kıyasla daha yüksektir. Bunun nedeni rahim içi dönemde kanın ve oksijenin adaptasyon amacı ile vital organlara yönlendirilmesinin neden olduğu barsak iskemisi ile açıklanmaktadır. ${ }^{[18]}$ Epidemiyolojik veriler erişkin yaşta görülen obezite, insülin direnci, diabetes mellitus, hipertansiyon ve kardiyovasküler hastalıkların IUBG ile doğan kişilerde daha sık olduğunu göstermektedir. [19]

IUBG tanısı alan bebeklerden doğumsal enfeksiyonu ve ağır doğumsal malformasyonu olanlar çıkarıldığın$\mathrm{da}$, geriye oldukça heterojen bir grup kalır. Geriye kalan bu bebeklerin entellektüel ve nörolojik fonksiyonları perinatal dönemde riskli olayların meydana gelip gelmemesine ve IUBG'nin spesifik nedenine bağlıdır. Serebral morbidite, doğum asfiksisine bağlı hipoksik iskemik ensefalopati sonucu gerçekleşmişse ya da postnatal dönemde hipoksi ve hipoglisemi geliştiyse etkilenme daha kötüdür. Bu perinatal olaylardan kaçınılmış olsa bile SGA olan bir bebek yine de gelişimsel sorunlar yaşayabilir. Özellikle baş çevresi ölçümünün göreceli olarak daha küçük olduğu, prematüritenin (doğum ağırlığı $<1500 \mathrm{~g}$ ) duruma eklendiği ya da postnatal dönemde normal sınırları yakalayacak hızlı büyümenin gerçekleşmediği durumlarda zekâ geriliği ve psikososyal problem gelişme riski yüksektir. ${ }^{[17]}$

\section{RISKLI BEBEĞE GENEL YAKLAŞIM}

Ayrıntılı bir perinatal öykü, çocuğun ilerideki dönemlerde hayatını etkileyebilecek risklerin erkenden fark edilmesini sağlayabilir. Bu nedenle, her bebeğin doğum haftası, doğum ağırlığı ve Apgar skorunun yanı sıra, tüm gebelik bilgileri not edilmelidir. Doğum eyleminin süresi ve doğum esnasında fetal kalp atımları ile ilgili problemlerin olup olmadığı mutlaka sorgulanmalıdır. ${ }^{[20]}$

Plasenta, umbilikal kord ve membranların doğumdan hemen sonraki dönemde incelenmesi hasta bir bebekte tanının teyit edilmesini sağlayabilmekte ya da bebekteki olası problemin, henüz semptomlar ortaya çıkmadan saptanabilmesini olanaklı kılabilmektedir. 
Fetal kan kaybı durumlarında plasenta soluk görülür, retroplasental kanama ve velamentöz kordda yırtıklar gözlenebilir. Fetofetal transfüzyon, doğumsal nefrotik sendrom, hidrops fetalis durumlarında plasentada ödem vardır. Amniyon nodosum ve oligohidramniyoz, pulmoner hipoplazi ve renal ageneziyi düşündürür. Plasenta üzerinde küçük beyaz nodül varlığı kandida enfeksiyonu lehinedir. Kısa ya da kıvrımsız umbilikal kord bazı kromozom anomalilerinde ve omfalosel durumlarında karşımıza çıkar. Gerçek umbilikal kord düğümleri tüm doğumların \%1'inden daha azında görülür; küçük fetüs, uzun kord, polihidramniyos, monoamniyotik ikizler, fetal ölüm ve düşük Apgar skorları ile ilişkilidir.

Koryoanjiyom varlığı prematürite, plasenta dekolmanı, polihidramniyos ve intrauterin gelişme geriliği ile ilişkilidir. Amniyos sıvısının mekonyum ile boyalı olması intrauterin stresi düşündürür ve plasentanın fetüse bakan yüzeyinin opak oluşu intrauterin enfeksiyon lehine bir bulgudur. Tek umbilikal arter varlığı da doğumsal renal anomali ile ilişkili olabilen bir bulgudur. [20] Ancak; prematüre doğan, doğum haftasına göre tartısı düşük olan, perinatal asfiksiye maruz kalan ve hayatı tehdit eden doğumsal anomali ile doğan birçok bebek için tanımlanmış bir risk faktörü mevcut değildir. Herhangi bir gestasyon haftası için doğum tartısı düştükçe ya da herhangi bir doğum ağırlığı için gebelik süresi kısaldıkça neonatal mortalite artmaktadır. Neonatal mortalite açısından en yüksek riskli grup doğum ağırlığı 1000 gr'ın ve gebelik haftası 28 haftanın altında olan bebeklerdir. Neonatal mortalite riskinin en düşük olduğu grup, doğum tartısı 3000-4000 gr ve gestasyonel yaşı 38-42 hafta olan bebeklerdir. Bunun yanında, tüm perinatal ölümlerin yaklaşık \%40'ı doğum ağırlığı 2500 gr ya da üstünde olan bebeklerde meydana gelmektedir. Bu ölümler doğumdan hemen önceki dönemde meydana gelmekte ve prematüre bebeklerin ölüm nedenlerinin aksine birçoğu potansiyel olarak önlenebilir etkenlere bağlı olmaktadır. ${ }^{[21]}$

illk iki yaşta aralıklı olarak nörolojik muayene yapılmalıdır. Preterm bebekler değerlendirilirken ilk iki yıl gestasyon yaşına göre düzeltilmiş yaş kullanılmalıdır. ${ }^{[22]} \mathrm{Bu}$ bebekler taburculuk sonrası her ay kontrole çağırılmalı ve kontrollerde ayrıntılı fizik ve nörolojik muayeneleri yapılmalıdır. Nörolojik muayene bulgularının bebeğin doğum haftasına ve gestayonel yaşına göre değişebileceği bilinmelidir.

Nörolojik muayenede genel durum (vital bulgular, uyku uyanıklık döngüsü, uyaranlara cevap, cilt muayenesi, baş çevresi ölçümü), fontaneller, motor fonksiyon, kraniyal sinirler, refleksler (derin tendon refleksleri, yüzeyel refleksler ve gelişimsel refleksler), duyu muayenesi ve bebeğin davranışları değerlendirilmelidir.
Baş çevresi ölçümü her muayenede mutlaka yapılmalıdır. Seri baş çevresi ölçümleri ile mikrosefali ve hidrosefali tanıları konulabilir. Fontanel gerginliği, kraniyal sütürlerde ayrılma, hızlı baş çevresi büyümesi, frontal çıkıntı, skafosefali ve baş çevresi ölçümünün boy uzunluğuna ölçümünün oranının yüksek olması hidrosefali açısından uyarıcı bulgulardır. Preterm bebeklerde baş çevresi büyüme hızı ilk 1-2 ay term bebeklerin yaklaşık iki katıdır $(1,1 \mathrm{~cm} / \mathrm{hafta})$. Üçüncü ve 4. aylardan itibaren ise preterm ve term bebeklerin baş çevresi büyüme hızları yaklaşık olarak aynıdır $(0,5 \mathrm{~cm} /$ hafta $) .{ }^{[21]}$

Tonus, bebeğin istirahatteki postürüne ve pasif harekete karşı kas direncine bakarak değerlendirilir. En sık anormal motor muayene bulgusu hipotonidir. Hipotonik bebekler kalça ve ekstremiteleri abduksiyonda, kurbağa pozisyonunda yatarlar; 28-30 haftanın altında doğan bebeklerde fizyolojik hipotoni, immatür postür ve motilite azlığı olabileceği akılda bulundurulmalıdır. Hipotoniye derin tendon reflekslerinde artışın eşlik etmesi santral sinir sistemi hasarını, hipertoni ve opistotonus piramidal ve ekstrapiramidal yolların hasarını düşündürür.

Yaşamın ilk yılında bebeklerin nörolojik muayenesinde postür, kas tonusu, ilkel refleksler (Tablo 4) ve postüral reaksiyonların (Tablo 5) değerlendirilmesi bir bütünlük oluşturur. ${ }^{[23,24]}$ Gelişimsel refleksler (primitif refleksler) yeni doğmuş ve riskli bebeklerin nörolojik olarak değerlendirilmesinde önemli bir bulgudur. Bunlar, beyin sapı kaynaklı, kompleks, otomatik hareketlerdir. Gelişimsel reflekslerin çoğu yenidoğan döneminde mevcuttur. Santral sinir sistemi gelişimi ile beraber serebral korteksin subkortikal motor sistemler üzerindeki inhibe edici etkisi kalktıkça bu reflekslerin kaybolması beklenir. Primitif reflekslerin olması gereken zamanda olmaması, kaybolmaları gereken zamanda devam etmeleri ve asimetrik olmaları, anormal muayene bulgularıdır. Moro refleksi 32. haftadan itibaren mevcuttur ve 3.-6. aylarda kaybolması beklenir. Adımlama refleksi 32. haftadan itibaren alınabilir ve 1-2 ayda kaybolması beklenir. Palmar ve plantar yakalama refleksleri 32. haftadan itibaren tespit edilir ve üç ay civarında kaybolur. Asimetrik tonik ense refleksi (ATNR) 35. gestasyonel haftadan itibaren tespit edilebilir ve 3.-4. düzeltilmiş ayda kaybolması beklenir. İstirahat durumunda ATNR'nin pozitif olması her zaman patolojiktir. Vojta, postüral reaksiyon anormallikleri ile santral koordinasyon bozuklukları arasındaki ilişkiyi göstermek için, yedi postüral reaksiyonun değerlendirildiği bir yöntem geliştirmiştir. En az dört anormal postüral reaksiyon gösteren bebeklerde serebral palsi gelişme riskinin daha yüksek olduğu gösterilmiştir. ${ }^{[23]}$ 
Tablo 4. Gelişimsel refleksler (primitif refleksler)

\begin{tabular}{|c|c|c|c|c|}
\hline Refleks & Pozisyon & Yöntem & Yanıt & Kaybolduğu yaş \\
\hline $\begin{array}{l}\text { Palmar } \\
\text { yakalama }\end{array}$ & Sırtüstü (supin) & $\begin{array}{l}\text { Bebeğin avuç içine işaret } \\
\text { parmağı konulur }\end{array}$ & $\begin{array}{l}\text { El parmaklarında } \\
\text { fleksiyon, yumruk yapma }\end{array}$ & 6. ay \\
\hline Plantar yakalama & Sırtüstü (supin) & $\begin{array}{l}\text { Sırtüstü ayak tabanına } \\
\text { parmakların hemen arka } \\
\text { kısmına parmakla bastırılır }\end{array}$ & $\begin{array}{l}\text { Ayak parmaklarında } \\
\text { fleksiyon }\end{array}$ & 15. ay \\
\hline Galant & Yüzükoyun (pron) & $\begin{array}{l}\text { Bebeğin sırt cildine spinöz } \\
\text { çıkıntıların } 2-3 \mathrm{~cm} \text { dış } \\
\text { kısmından omuzlardan } \\
\text { aşağı doğru parmakla } \\
\text { çizilir gibi yapılır }\end{array}$ & $\begin{array}{l}\text { Uyarı yapılan tarafa doğru } \\
\text { konkavite oluşturacak } \\
\text { şekilde gövdede bükülme }\end{array}$ & 4. ay \\
\hline $\begin{array}{l}\text { Simetrik tonik boyun } \\
\text { refleksi }\end{array}$ & $\begin{array}{l}\text { Farklı pozisyonlarda; } \\
\text { sırtüstü; el ve dizler zemine } \\
\text { değecek şekilde veya } \\
\text { oturur pozisyonda }\end{array}$ & $\begin{array}{l}\text { Baş öne doğru eğilir } \\
\text { (boyun fleksiyonu) } \\
\text { Baş arkaya doğru kaldırılır } \\
\text { (boyun ekstansiyonu) }\end{array}$ & $\begin{array}{l}\text { Üst ekstremitelerde } \\
\text { fleksiyon, alt } \\
\text { ekstremitelerde } \\
\text { ekstansiyon } \\
\text { Üst ekstremitelerde } \\
\text { ekstansiyon, alt } \\
\text { ekstremitelerde fleksiyon }\end{array}$ & 6-7. aylar \\
\hline $\begin{array}{l}\text { Asimetrik tonik boyun } \\
\text { refleksi }\end{array}$ & Sırtüstü & $\begin{array}{l}\text { Bebeğin başı bir tarafa } \\
\text { doğru döndürülür ve } \\
15 \text { saniye boyunca bu } \\
\text { pozisyonda tutulur }\end{array}$ & $\begin{array}{l}\text { Çene tarafındaki } \\
\text { ekstremitelerde } \\
\text { ekstansiyon, oksipital } \\
\text { taraftaki ekstremitelerde } \\
\text { fleksiyon }\end{array}$ & 3. ay \\
\hline Suprapubik ekstansör & Sırtüstü & $\begin{array}{l}\text { Pubik kemik üzerindeki } \\
\text { cilde parmaklarla baskı } \\
\text { uygulanır }\end{array}$ & $\begin{array}{l}\text { Her iki alt ekstremitede } \\
\text { refleks olarak ekstansiyon } \\
\text { ile talipes ekinus } \\
\text { oluşturacak şekilde } \\
\text { adduksiyon ve içe } \\
\text { rotasyon }\end{array}$ & 4. hafta \\
\hline Çapraz ekstansör & Sırtüstü & $\begin{array}{l}\text { Bir bacak pasif olarak tam } \\
\text { fleksiyona getirilir }\end{array}$ & $\begin{array}{l}\text { Diğer bacakta ekstansiyon } \\
\text { ile talipes ekinus } \\
\text { oluşturacak şekilde } \\
\text { adduksiyon ve içe } \\
\text { rotasyon }\end{array}$ & 6. hafta \\
\hline Rossolimo & Sırtüstü & $\begin{array}{l}\text { Ayak 2.-4. parmaklarının } \\
\text { plantar yüzeyine refleks } \\
\text { çekici ile hafifçe vurulur }\end{array}$ & $\begin{array}{l}\text { Ayak parmaklarında } \\
\text { birinci metakarpofalangeal } \\
\text { eklemde tonik fleksiyon }\end{array}$ & 4. hafta \\
\hline Topuk & Sırtüstü & $\begin{array}{l}\text { Kalça ve diz eklemi } \\
\text { fleksiyonda, ayak bileği } \\
\text { nötral pozisyonda iken } \\
\text { refleks çekici ile topuğa } \\
\text { hafifçe vurulur }\end{array}$ & $\begin{array}{l}\text { Bacakta hızlı ekstansiyon } \\
\text { refleksi }\end{array}$ & 3. hafta \\
\hline Moro & Sırtüstü & $\begin{array}{l}\text { Başın hafifçe geriye } \\
\text { düşmesi ile oluşturulan } \\
\text { ani baş ekstansiyonu }\end{array}$ & $\begin{array}{l}\text { Üst ekstremitelerde } \\
\text { abduksiyonu takiben } \\
\text { adduksiyon ve fleksiyon }\end{array}$ & 6. ay \\
\hline Babinski & Sırtüstü & $\begin{array}{l}\text { Topuktan } 5 \text {. metatarsal } \\
\text { kemiğin baş kısmına doğru } \\
\text { ayağın yan tarafı boyunca } \\
\text { çizilir gibi yapılır }\end{array}$ & $\begin{array}{l}\text { Birleşik ekstansör } \\
\text { yanıt: başparmakta } \\
\text { dorsifleksiyon ile } \\
\text { eşzamanlı olarak diğer } \\
\text { parmaklarda yelpaze gibi } \\
\text { açılma }\end{array}$ & $\begin{array}{l}\text { Bebeklerin çoğunda } 1 \\
\text { yaşına kadar ekstansör } \\
\text { plantar yanıt alınabilir, } \\
\text { gerçek Babinski yanıtı her } \\
\text { zaman patolojiktir }\end{array}$ \\
\hline
\end{tabular}


Tablo 5. Postüral reaksiyonlar

\begin{tabular}{|c|c|c|}
\hline Reaksiyon & Pozisyon & Yöntem \\
\hline Traksiyon & Sırtüstü (supin) & $\begin{array}{l}\text { İşaret parmakları bebeğin avuçlarına konur ve bebek muayene yatağından } 45 \text { derece } \\
\text { açı oluşturacak şekilde çekilir }\end{array}$ \\
\hline Horizontal süspansiyon & Yüzükoyun (pron) & $\begin{array}{l}\text { Eller bebeğin başını veya bacaklarını desteklemeyecek ve toraksı çevreleyecek şekilde } \\
\text { yerleştirilir, bebek aşağı doğru sarkıtılır }\end{array}$ \\
\hline Vertikal süspansiyon & Dik (vertikal) & $\begin{array}{l}\text { Her iki el toraksı sıkıştırmayacak şekilde aksillaya yerleştirilir, bebeğin yüzü muayene } \\
\text { eden kişiye bakacak şekilde yukarı doğru kaldırılır }\end{array}$ \\
\hline Vojta yanıtı & Dik & $\begin{array}{l}\text { Bebeğin yüzü muayene eden kişiye dönükken eller toraksı çevreleyecek şekilde } \\
\text { yerleştirilir, bebek dik pozisyondan yatay pozisyona gelecek şekilde sarkıtılır }\end{array}$ \\
\hline $\begin{array}{l}\text { Kollis horizontal } \\
\text { süspansiyonu }\end{array}$ & Yüzükoyun & $\begin{array}{l}\text { Bir el kolun diğer el ise bacağın üst kısmını kavrayacak şekilde yerleştirilir ve bebek } \\
\text { muayene yatağına paralel bir şekilde yatay pozisyonda sarkıtılır }\end{array}$ \\
\hline Kollis vertikal süspansiyonu & Yüzükoyun & $\begin{array}{l}\text { Bir el bacağın üst kısmını kavrayacak şekilde yerleştirilir ve bebek dik pozisyonda baş } \\
\text { aşağı sarkıtılır }\end{array}$ \\
\hline $\begin{array}{l}\text { Peiper-Isbert vertikal } \\
\text { süspansiyonu }\end{array}$ & Yüzükoyun & $\begin{array}{l}\text { Muayene eden kişi ellerini bebeğin her iki bacağının üst kısmını kavrayacak şekilde } \\
\text { yerleştirir ve bebeği dik pozisyonda baş aşağı sarkıtır }\end{array}$ \\
\hline
\end{tabular}

Kraniyal sinirlerin muayenesinde 1. ve 9. sinirin değerlendirilmesi yenidoğan döneminde zordur. İkinci sinirin muayenesi ise, görme yanıtları gestasyonel yaşla arttığı için bebeğin gestasyonel haftasına göre değerlendirilir. Yirmi altı haftalık bebek ışık uyaranı ile gözünü kırpabilir, 32. haftada tespit yapabilir, 34. haftada renkli objeyi izleyebilir, 37. haftada ışığı takip edebilir. Otuz altıncı haftada optokinetik nistagmus değerlendirilebilir. Otuz beşinci haftada ışık refleksinin pozitif olması, 2. ve 3 . kraniyal sinirin normal olduğunu gösterir. Taş bebek gözü manevrası 25 . haftadan itibaren uygulanabilir. Baş ve boyun bir tarafa çevrildiğinde gözlerin karşı tarafa konjuge olarak kayması 3. ve 6 . sinirin normal olduğunu gösterir. Spontan, ani başlangıçlı horizontal göz hareketleri nöbet bulgusu olabilir. Gözlerin horizontal tonik olarak bir tarafa kayması, santral sinir sistemi hasarı bulgusudur. Gözlerde aşağı doğru tonik kayma kafa içi basınç artışı bulgusudur. Yirmi sekizinci haftadan itibaren 8. siniri sağlam olan bir bebek ani sesle irkilebilir. Emme ve yutmanın koordinasyonu ile 5., 7., 9., 10., ve 12. sinirler değerlendirilebilir. Öğürme refleksin olmaması 9. ve 10 . kraniyal sinir hasarının bulgusudur.

Duyu muayenesi yenidoğanda zordur ve genellikle uygulanmaz. Yüksek kortikal işlevler, yenidoğanın davranışlarının değerlendirilmesi ile araştırılabilir. Örneğin; beyin hasarı olan bebekler ağladıklarında sağlıklı olan bebeklere göre daha uzun sürede sakinleştirilebilirler.
Sağıklı bebekler tekrarlayan ses ve ışık uyarılarına giderek azalan cevap verirken, beyin hasarı olan bebekler giderek artan yanıt verirler.

Bu muayeneler sırasında huzursuzluk, hipotoni, hipertoni, anormal postür, primitif reflekslerin devam etmesi serebral palsi bulgusudur. Bebeklerin ayına uygun motor becerilerinin gelişmemesi de önemli bir serebral palsi bulgusudur. Ayına uygun motor beceriler Tablo 6'da sunulmuştur. ${ }^{[22]}$

Riskli bebeklerin takibinde ya da saptanmasında bazı gelişimsel tarama testleri kullanılmaktadır. Bu gelişimsel tarama testleri 6-12 ayda, 1-3 yaşlarında ve okul öncesinde yapılmalıdır. Bunlar içinde en sık kullanılanlar Denver Gelişimsel Tarama Testi ve Bayley testidir. Denver Gelişimsel Tarama Testi 1980 yılında Türk çocukları için standardize edilerek kullanıma sunulmuştur. ${ }^{[25]}$ Denver Gelişimsel Tarama Testi görünüşü normal olan çocuklarda doğumdan itibaren altı yaşına kadar uygulanır. Değerlendirmede 125 adet iyi standardize edilmiş test sorusu ya da aracı vardır. Bu test ile ince motor, kaba motor, kişisel-sosyal beceriler ve dil becerileri değerlendirilir. Eğer iki ya da daha fazla gecikme saptanırsa, çocuk testi geçememiştir ve daha ayrıntılı bir gelişimsel değerlendirmeye ihtiyaç vardır. Bayley taraması dogumdan sonra 24. aya kadar olan bebeklerde uygulanabilir. Bu test ile ince motor, kaba motor, dil ve sosyal etkileşim ve oyun becerileri incelenmektedir. Testin sonunda çocuk gelişim geriliği açısından 
Tablo 6. Gelişim basamakları

\begin{tabular}{|c|c|c|c|}
\hline Yaş & Motor Beceri & Yaş & Motor Beceri \\
\hline 2 ay & $\begin{array}{l}\text { Ellerini genellikle yumruk yapar } \\
\text { Yüzükoyun yatırılı̆̆ında başını yerden kaldırabilir } \\
\text { Objeyi gözleri ve başı ile } 90 \text { derece takip eder } \\
\text { Tek heceli sesler çıarır }\end{array}$ & $9-10$ ay & $\begin{array}{l}\text { Desteksiz oturur, oturma pozisyonuna geçebilir } \\
\text { Bir yerden tutunarak ayakta durabilir } \\
\text { El sallar ve "bay-bay"der } \\
\text { Yardımla bardaktan su içebilir } \\
\text { Baş ve işaret parmağını kullanarak cisimleri alabilir }\end{array}$ \\
\hline 3 ay & $\begin{array}{l}\text { Ellerini daha az yumruk yapar } \\
\text { Yüzükoyun başını yerden kaldırıp bir süre öyle tutabilir } \\
\text { Objeleri elinde kısa süreli tutabilir } \\
\text { Başını döndürerek gözleri ile objeyi her yönde izler } \\
\text { Karşııkı konuşmaya gülerek ve ses çıkartarak tepki verir } \\
\text { Ellerine ve annesinin yüzüne bakar } \\
\text { Sesli güler }\end{array}$ & $11-12$ ay & $\begin{array}{l}\text { Yardımla yürüyebilir } \\
\text { Birkaç anlamlı kelime söyleyebilir } \\
\text { Giyinirken yardım etmek ister } \\
\text { Basit emirleri yerine getirir }\end{array}$ \\
\hline 4 ay & $\begin{array}{l}\text { Otururken başını devamlı olarak dik tutabilir } \\
\text { Cisimlere uzanır ve eliyle ağzına götürür } \\
\text { Ses gelen yöne doğru başını çevirebilir }\end{array}$ & $13-15$ ay & $\begin{array}{l}\text { Kendisi yürüyebilir } \\
\text { Kelime sayısı artmıştır } \\
\text { Kalemle karalama yapabilir } \\
\text { İstediği objeyi gösterebilir }\end{array}$ \\
\hline $5-6$ ay & $\begin{array}{l}\text { Sırtüstü yatarken başını yerden kaldırabilir } \\
\text { Yüzükoyun pozisyondan sırtüstü dönebilir } \\
\text { Objeyi bir elinden diğerine geçirebilir } \\
\text { Kendi kelimeleri ile konuşur } \\
\text { Destekle oturur }\end{array}$ & 18 ay & $\begin{array}{l}\text { Daha düzgün yürüyebilir } \\
\text { Yardımla merdiven çıkabilir } \\
\text { Topu karşısındakine atabilir } \\
\text { 2-4 küpü üst üste koyabilir } \\
\text { Kendi yemeğini yiyebilir } \\
\text { Göz ve kulak gibi organları gösterebilir }\end{array}$ \\
\hline $7-8$ ay & $\begin{array}{l}\text { Ellerinden destek alarak oturabilir } \\
\text { Objeleri masaya vurur } \\
\text { Kolları ile karşısındaki kişiye uzanabilir } \\
\text { "de-de, ba-ba" hecelerini söyler }\end{array}$ & 24 ay & $\begin{array}{l}\text { Koşar } \\
2-3 \text { kelimelik cümle kurabilir } \\
\text { Kitap sayfalarını çevirebilir } \\
\text { 4-6 küpten kule yapabilir } \\
\text { "Sen, ben" kavramları kullanabilir }\end{array}$ \\
\hline
\end{tabular}

hafif, orta veya yüksek riskli olarak kategorize edilir. Uygulaması kolay ve yaklaşık 10 dakika süren bir testtir. ${ }^{[26]}$ Motor gerilik ya da spastisite saptanan bebeğe doğru pozisyon verilmesi konusunda, fizyoterapistler aileyi eğiterek ya da erken motor tedaviler uygulayarak çocuğun ve ailenin yaşam kalitesinin arttırılmasına katkıda bulunurlar.

Bebeğin büyümesi, gelişmesi, beslenmesi ve aşılanması her kontrolde değerlendirilir. Prematüreler 1 . ayda ve retina damarlanması tamamlanana kadar her hafta göz doktoru tarafından izlenirler. Kırma kusurları ve şaşılık açısından iki yaşına kadar altı ayda bir değerlendirilme yapılmalıdır. İlk üç ay içerisinde işitme problemleri açısından tarama yapılmalıdır. İhtiyaç durumunda bebeklere koklear implant ve işitme cihazı önerilmelidir.

VLBW bebekler taburcu olduktan sonra riskli bebek izlem polikliniklerinde takip edilmelidirler. Bu konuda deneyimli olmayan hekimlerin bu hastaları uygun merkezlere yönlendirmeleri tanıda ve tedavide gecikmeleri önleyecektir.

$\mathrm{Bu}$ bebeklerin takibinde yenidoğan uzmanı, çocuk gelişim uzmanı, fizyoterapist, odyolog, konuşma ve dil terapisti, solunum terapisti, oftalmolog ve diyetisyen görev almalıdır. Gerektiğinde çocuk nöroloji, ortopedi, çocuk cerrahisi, kardiyoloji ve göz hastalıkları uzmanlarından konsültasyon istenmelidir.

Sonuç olarak; gelişim geriliği olan bebeklerin erken dönemde tespit edilmesi uygun girişimin zamanında başlatılması açısından çok önemlidir. Gelişim geriliğini erken dönemde fark etmek her zaman kolay olmamakla birlikte bu bebeklerin fark edilmesi ve gerektiğinde yönlendirilmeleri söz konusu olduğunda, birinci basamak hekimleri hayati bir role sahiptir. Bu bebeklerin zamanında tanı alabilmesi için anamnezlerinin iyi alınması ve fizik muayenelerinin ve gelişim testlerinin ayrıntılı yapılması gerekmektedir. Belirgin bir sorun saptanamasa bile, bu bebeklerin takibi belli aralıklarla sürmelidir. 


\section{KAYNAKLAR}

1. WHO, March of Dimes, Partnership for Maternal, Newborn \& Child Health, Save the Children. Born too soon: The global action report on preterm birth. Edited by: Howson CP, Kinney M, Lawn JE. Geneva, 2012.

2. Blencowe $H$, Cousens S, Oestergaard MZ, Chou D, Moller AB, Narwal R, Adler A, Vera Garcia C, Rohde S, Say L, Lawn JE. National, regional, and worldwide estimates of preterm birth rates in the year 2010 with time trends since 1990 for selected countries: a systematic analysis and implications. Lancet 2012;379(9832):2162-72. Crossref

3. Tyson JE, Parikh NA, Langer J, Green C, Higgins RD; National Institute of Child Health and Human Development Neonatal Research Network. Intensive care for extreme prematurity--moving beyond gestational age. N Engl J Med 2008;358(16):1672-81. Crossref

4. Wood NS, Marlow N, Costeloe K, Gibson AT, Wilkinson AR. Neurologic and developmental disability after extremely preterm birth. EPICure Study Group. N Engl J Med 2000;343(6):378-84. Crossref

5. Johnson S, Fawke J, Hennessy E, Rowell V, Thomas S, Wolke D, Marlow N. Neurodevelopmental disability through 11 years of age in children born before 26 weeks of gestation. Pediatrics 2009;124(2):e249-57. Crossref

6. Moore T, Hennessy EM, Myles J, Johnson SJ, Draper ES, Costeloe K, Marlow N. Neurological and developmental outcome in extremely preterm children born in England in 1995 and 2006: the EPICure studies. BMJ 2012;345(3):e7961. Crossref

7. Larroque B, Ancel PY, Marret S, Marchand L, André M, Arnaud C, Pierrat V, Rozé JC, Messer J, Thiriez G, Burguet A, Picaud JC, Bréart G, Kaminski M; EPIPAGE Study group. Neurodevelopmental disabilities and special care of 5-year-old children born before 33 weeks of gestation (the EPIPAGE study): a longitudinal cohort study. Lancet 2008;371(9615):813-20. Crossref

8. Ishii N, Kono Y, Yonemoto N, Kusuda S, Fujimura M; Neonatal Research Network, Japan. Outcomes of infants born at 22 and 23 weeks' gestation. Pediatrics 2013;132(1):62-71. Crossref

9. Serenius $F$, Källén K, Blennow $M$, Ewald U, Fellman V, Holmström G, Lindberg E, Lundqvist P, Maršál K, Norman M, Olhager E, Stigson L, Stjernqvist K, Vollmer B, Strömberg B; EXPRESS Group. Neurodevelopmental outcome in extremely preterm infants at 2.5 years after active perinatal care in Sweden. JAMA 2013;309(17):1810-20. Crossref

10. Luu TM, Ment LR, Schneider KC, Katz KH, Allan WC, Vohr BR. Lasting effects of preterm birth and neonatal brain hemorrhage at 12 years of age. Pediatrics 2009;123(3):103744. Crossref

11. Levene ML, Kornberg J, Williams TH. The incidence and severity of post-asphyxial encephalopathy in full-term infants. Early Hum Dev1985;11(1):21-6. Crossref
12. Sarnat HB, Sarnat MS. Neonatal encephalopathy following fetal distress -a clinical and electroencephalographic study. Arch Neurol 1976;33(10):696-705. Crossref

13. Stamos JK, Rowley AH. Timely diagnosis of congenital infections. Pediatr Clin North Am 1994;41(5):1017-33. Crossref

14. Stoll BJ. Infections of the neonatal infant. In: Kliegman $\mathrm{R}$, Nelson WE, editors. Nelson Textbook of Pediatrics. Philadelphia: Elsevier Saunders; 2011. p.637.

15. Rosenberg A. The IUGR Newborn. Semin Perinatol 2008;32(3):219-24. Crossref

16. Regev RH, Lusky A, Dolfin T, Litmanovitz I, Arnon S, Reichman $B$; Israel Neonatal Network. Excess mortality and morbidity among small-for-gestational-age premature infants: a population based study. J Pediatr 2003;143(2):186-91. Crossref

17. Snijders RJM, Abbas A, Melby O, Ireland RM, Nicolaides $\mathrm{KH}$. Fetal plasma erythropoietin concentration in severe growth retardation. Am J Obstet Gynecol 1993;168(2):615-19. Crossref

18. Kempley ST, Gamsu HR, Vyas S, Nicolaides K. Effects of intrauterine growth retardation on postnatal visceral and cerebral blood flow velocity. Arch Dis Child 1991;66(10):1115-18. Crossref

19. Barker D. Fetal programming of coronary artersy disease. Trends Endocrinol Metab 2002;13(9):363-8. Crossref

20. Waldemar AC. The newborn infant, Chap. 88. In: Kliegman R, Nelson WE, editors. Nelson Textbook of Pediatrics. Philadelphia: Elsevier Saunders; 2011. p.532-9.

21. Waldemar AC. Overview of mortality and morbidity, Chap. 87. In: Kliegman R, Nelson WE, editors. Nelson Textbook of Pediatrics. Philadelphia, PA: Elsevier Saunders; 2011. p.532.

22. Swaiman K. Neurological examination of the term and preterm infant. In: Swaiman KF, Ashwal S, Ferriero DM, editors. Pediatric Neurology: Principle and Practice, 4th ed. Philadelphia, PA: Mosby Elsevier; 2006. p.794-5.

23. Vojta V. Die cerebralen Bewegungstoerungen im Kindesalter, 4te auflage. Stuttgart: Ferdinand Enke Verlag; 1988.

24. Zafeiriou DI. Primitive reflexes and postural reactions in the neurolodevelopmental examination. Pediatr Neurol 2004;31(1):1-8. Crossref

25. Yalaz K, Epir S. The Denver Developmental Screening test: normative data for Ankara children. Turk J Pediatr 1983;25(4):245-58.

26. Bayley N. Bayley Scales of Infant and Toddler Development, 3rd ed. San Antonio, TX, USA: Harcourt Assessment; 2006. 